\title{
The theory and practice of flipped classroom based on spoken English
}

\author{
Yiling Li \\ School of North China Electric Power University, HeBei 071000, China \\ 1415066960@qq.com
}

Keywords: flipped classroom, spoken English, pattern design, teaching practice

\begin{abstract}
With the world rapidly urbanizing, the phenomenon of urban sprawl is prominent, and long - term and sustainable urban planning development is of great importance. Smart growth is an urban planning theory with great superiority. This paper studies the evaluation of smart growth on urban development, in order to give a reference on the process of urban development. In the essay, establish an original three-grade evaluation system then take use of directed graph to analyze indexes of system. Finally get the definition of the success of smart growth of a city through impulse process modeling.
\end{abstract}

\section{Introduction}

Flipped classroom origins in the United States, as a new teaching ideas and methods which is different from traditional teaching, has become the reform hot spots concerned by the global education sector. Flipped classroom has the unique advantages which traditional classroom don't own, and applying it to teaching practice will improve class learning quality. Although flipped classroom has been implemented in the United States with a wide range, and it has been highly praised and widely recognized by the United States teachers and students. However, in China, the study and application of the transition is still in its infancy. It is very important for college students to develop spoken English. However, there are many problems exist. Many students is not confident enough, so they wouldn't like to say English, the communication in class cannot be effective. Moreover, the students are little interest in spoken English, most of them learn it in order to go abroad or work. Learn based on utilitarianism cannot bring substantial improvements. In addition, the level of students' spoken English is different, so that teachers cannot meet differences to everyone. The popular teaching will reduce the efficiency of class.

\section{The advantages of flipped classroom on oral English}

\subsection{Enhance students' self-confidence in spoken English}

In the traditional classroom of spoken English, there is such a phenomenon that when having practice for spoken English in class, because many student cannot master it in short time, they are too shy to speak English on the presentation. Gradually, it would shorten the confidence of students on speaking English, which is a vicious circle and students stop learning spoken English. However, on the model of flipped classroom, students learn knowledge at home by themselves, they can do more practices to improve the spoken English where cannot be mastered in a short time. And on the presentation they can show the best in class, which can enhance their self-confidence.

\subsection{Cultivate students' interest in learning independently}

Flipped classroom mode can provide a variety of pre-class learning content and form, which cannot be replaced by traditional classroom. If the course content is boring and the form is single, which is difficult to stimulate students' interest in learning, so students are not supposed to learn. One of the great benefits of flipped classroom is the large range of pre-class learning. Pre-class study don't have too many restrictions not like class, so pre-class learning can add something that students are interested in such as animation, music, movies and so on, and also can change the form. Diversified content and form can greatly stimulate students' interest in learning independently. Once students have interest, they will be positive, and the learning effect will be more prominent. 


\subsection{To meet individual differences}

The traditional classroom is unified teaching, all the content of learning to everyone are the same. But the level of individual students are different, For some students whose foundation are not good, even if the teacher meets the needs of most students as much as possible, sometimes it is difficult to keep up with the rhythm for those students; for some students whose foundation are good, the teacher repeatedly explained the knowledge which they has been mastered, it will reduce efficiency, the class time is not be well used. On the model of flipped classroom, students finish mastering the knowledge before class by themselves, and they can selectively learn according to their own degree of foundation. For example, the students with the weak foundation can do practice repeated, first enhance the basis of knowledge. The students with the good foundation can simply review the basic knowledge, focusing on grasp the complicated content to improve. On this way, it can be better to meet the individual differences.

\subsection{The flip of roles between teachers and students, which improve efficiency}

Students like humorous, relaxed environment, students is passive in the traditional classroom, always do not want to participate in activities of class. In the classroom activities, there is always a long silence time after the teacher asked the question. However, flipped classroom achieve the flip of role between students and teachers. On the personalized teaching mode of flipped classroom, students become the protagonist of the whole process of learning, is a self-timid learners. Due to pre-class learning with a certain degree, students can grasp the keys of the class, think positively and look for the answer with questions. It enhances the students' sense of ownership in the classroom, so that students will participate in the classroom activities positively and the interaction will become more effective.

\section{Flip the classroom practice}

The author has the following cases that carry out a small-scale flip classroom on spoken English in the relevant research topics.

We organized the flipped classroom in the spoken English consisting of three parts: one is the pre-class module, including the video, the document, the online practice, they are sent to the subject participant through the network, who completed them before the class; one is class module, including the group discussion, the teacher explain the question put forward, and balance pre-class modules; another is comprehensive testing, in order to reflect the effect of the classroom, we test the participants about spoken English before and after the subject, whose standard refer to IELTS . And we get scores for participants.

\begin{tabular}{|c|c|c|c|c|c|c|c|c|c|c|}
\hline \multirow[t]{2}{*}{$\begin{array}{l}\text { items } \\
\text { Serial } \\
\text { number }\end{array}$} & \multicolumn{2}{|c|}{$\begin{array}{c}\text { Fluency and } \\
\text { coherence }\end{array}$} & \multicolumn{2}{|c|}{ Vocabulary } & \multicolumn{2}{|c|}{$\begin{array}{c}\text { Grammar } \\
\text { structure and the } \\
\text { accuracy of } \\
\text { story repetition }\end{array}$} & \multicolumn{2}{|c|}{ pronunciation } & \multicolumn{2}{|c|}{$\begin{array}{c}\text { The average } \\
\text { score }\end{array}$} \\
\hline & before & later & before & later & before & later & before & later & before & later \\
\hline 1 & 5 & 7 & 5 & 7 & 4 & 7 & 5 & 5 & 4.00 & 6.25 \\
\hline 2 & 5 & 8 & 6 & 7 & 4 & 6 & 4 & 5 & 4.75 & 6.50 \\
\hline 3 & 5 & 8 & 4 & 7 & 4 & 7 & 5 & 6 & 4.50 & 7.00 \\
\hline 4 & 5 & 7 & 5 & 8 & 6 & 6 & 4 & 5 & 5.00 & 6.00 \\
\hline 5 & 5 & 8 & 4 & 8 & 5 & 6 & 5 & 6 & 4.75 & 6.50 \\
\hline 6 & 6 & 8 & 5 & 7 & 5 & 7 & 5 & 6 & 5.25 & 7.00 \\
\hline 7 & 5 & 7 & 6 & 7 & 5 & 6 & 4 & 5 & 5.75 & 6.25 \\
\hline 8 & 5 & 8 & 6 & 8 & 5 & 6 & 4 & 6 & 6.25 & 6.75 \\
\hline 9 & 5 & 7 & 5 & 7 & 5 & 6 & 4 & 6 & 4.75 & 6.50 \\
\hline 10 & 6 & 8 & 5 & 7 & 5 & 7 & 4 & 6 & 5.00 & 5.75 \\
\hline 11 & 4 & 7 & 5 & 8 & 5 & 6 & 5 & 6 & 4.75 & 6.75 \\
\hline 12 & 5 & 8 & 5 & 7 & 6 & 8 & 4 & 6 & 5.00 & 6.25 \\
\hline 13 & 6 & 8 & 5 & 7 & 4 & 6 & 4 & 6 & 4.75 & 6.75 \\
\hline 14 & 5 & 8 & 6 & 7 & 4 & 6 & 5 & 5 & 5.00 & 6.50 \\
\hline 15 & 5 & 8 & 6 & 8 & 4 & 6 & 4 & 5 & 4.75 & 6.25 \\
\hline
\end{tabular}


Subject research lasted two months, from the results of test, $66.7 \%$ of the participants have obvious improvements in spoken English. After the research course finished, the author organized an interview with the participants in the project about the various aspects of participation, mode design and participation feelings, then learned about the feasibility and adaptability of the flipped classroom model in spoken English. According to the answers of the participants, many students think that this model is more than the traditional classroom to let them desire to learn and increase the interaction in learning. Based on the interview, the author summaries the problems that participants put forward in practice.

First, long study time will affect the students' interest in learning, and students will produce burnout emotions. Second, learning content should be vary as much as possible, a participant mentioned the film dubbing in the previous course attracted them. So if this aspect can be improved, it can enhance students' interest in learning. Third, the classroom inquiry often only stay in a simple group discussion, did not realize the internalization of the knowledge and the teacher's guidance may be insufficient, which also affected the mode applied to the spoken English learning.

\section{Key points of the classroom practice}

\subsection{The role of teachers positioning}

Teachers transform knowledge teaching into learning facilitator and mentor, and the student's main position in the flipped classroom be fully reflected. Teachers should adjust their minds, change their thoughts, release them from the absolute right to speak in the past, and play the role of instructors who help students to learn and explain doubts. As a mentor, teachers should understand the individual differences in the students, so that design pre-class learning with different gradients to guide the class learning and meet the individual needs, abandon the original monotony of teaching, which also bring higher requirements to teachers in resources Integration, judgment, professionalism and other aspects .

\subsection{The production of teaching video}

The production of teaching video is essential, its quality directly affects the students' learning interest and learning effect. In the aspect of time, micro-video is generally in 15-20 minutes, the video is too short to show all knowledge points, and if the video is too long, students may produce burnout, which can be shown in the interview of research. In the aspect of content, the teaching video generally includes a brief introduction to the subject, text reading, explaining the knowledge points, design online training and other necessary steps .And teachers should streamline the content as much as possible to achieve the ideal results. In addition, the video can be added in a variety of forms, such as music, animation and so on. The above-mentioned film dubbing is very popular with students, if necessary, it can also add highlights to the teaching video

\subsection{Realize the thorough inquiry in the class.}

Thorough inquiry is the most important part in class. There are two parts to determine the success or failure of thorough inquiry. One is the form of it, the author found that in the flipped classroom curriculum, teachers sometimes would organize the discussion among students to solve the problems they met in before-class video ,but the discussion cannot take ideal effect at the most of time in the class.The differences among students lead to kinds of problems they met , and large class and big amounts of group on the discussion cause that the guidance of teacher are inadequate. The other is the content of thorough inquiry, which requires teachers design appropriate topics according to teaching experience and the progress of students' learning. If the students only grasp the simple knowledge through the topic ,it still cannot take effect .

\section{References}

[1] Jinlei Zhang.The Key Factors Analysis of the Teaching Model of the Flipped Classroom[J]. Distance Education In China ,2013,(10):59-64

[2] Haiyan LU.The Feasibility Analysis of the Application about Flipped Classroom’s Model Based 
on Micro-class[J].CAFLE,2014,(4):33-36

[3] Chaoyang He,Yufang Ou,Qi Cao.USA Universities’ Inverted Classroom Teaching Model[J]. High Engineering Education Research,2014,(2):148-151 